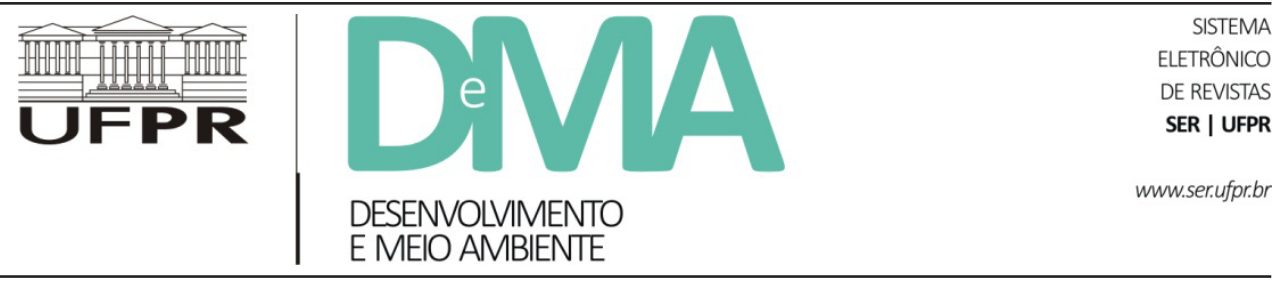

\title{
A relação entre comercialização de alimentos e princípios agroecológicos na rede de cooperativas de reforma agrária do Paraná/Brasil
}

\section{The Relationship Between Food Marketing and Agroecological Principles in the Agrarian Reform Cooperatives Network from Paraná/Brazil}

\author{
Oscar José ROVER ${ }^{1}$, Ademir de Jesus RIEPE ${ }^{2 *}$ \\ ${ }^{1}$ Universidade Federal de Santa Catarina (UFSC), Florianópolis, SC, Brasil. \\ ${ }^{2}$ Cooperativa de Comercialização Camponesa Vale do Ivaí Ltda (COCAVI), Jardim Alegre, PR, Brasil. \\ *E-mail de contato: ademirjriepe@gmail.com
}

Artigo recebido em 2 de julho de 2015, versão final aceita em 8 de julho de 2016.

RESUMO: O artigo analisa a (in)compatibilidade entre dinâmicas de comercialização de alimentos e princípios agroecológicos, estudando uma rede de cooperativas de reforma agrária. Foram consideradas as categorias "diversidade de alimentos" e "proximidade entre produção e consumo", entendidas como chaves para uma abordagem agroecológica. Verificamos que o envolvimento com os mercados promove em algumas cooperativas uma forte especialização e possibilita a venda para mercados distantes, enquanto em outras se vê a valorização da diversidade e dos mercados de proximidade, porém, com dependência dos mercados institucionais. Concluímos que há caminhos possíveis para se especializar e ampliar a escala comercial sem se afastar de princípios agroecológicos.

Palavras-chave: agricultura familiar; agroecologia; circuitos curtos de comercialização; redes agroalimentares alternativas; mercados de proximidade.

ABSTRACT: The article analyzes the (in) compatibility between food market dynamics and agro ecological principles, studying a network of cooperatives created by agrarian reform farmers. The categories "food diversity" and "proximity between production and consumption" were analyzed as key contributors to the agro ecological approach. The research verifies that the involvement in food markets leads to the development of specialization and sale to distant markets in some cooperatives, while others value production diversity and integration with local markets, despite their heavy dependence of institutional markets. The study concludes that there are alternative paths of specialization and increase of commercial scales, respecting agro ecological principles.

Keywords: family farming; agroecology; short food supply chain; alternative food networks; local markets. 


\section{Introdução}

Os agricultores familiares e suas organizações exercem importante contribuição para a sociedade, mediante o fornecimento de alimentos variados que vão ao encontro do desejo dos consumidores por alimentos de melhor qualidade biológica e organoléptica. Consumir alimentos com essas qualidades contribui para o enfrentamento de problemas de saúde pública, muitos provocados pelo "jeito moderno de se alimentar", a partir de alimentos industrializados e ultraprocessados.

Os mercados de alimentos apresentam cada vez mais exigências quanto aos padrões de qualidade e conformidade, os quais podem ser vistos como oportunidades de desenvolvimento e também como fatores de exclusão, a depender da capacidade de adequação dos produtores. Os mercados exercem pressão sobre as formas de organização produtiva e comercial na agricultura familiar. Isto muitas vezes gera exclusão e seletividades, permanecendo apenas aqueles que se adequam às exigências dos mercados, porém, em outros casos geram resistências e novas formas de organização, por exemplo, por meio de processos associativos e cooperativos. Uma forma que muitos agricultores e suas organizações têm buscado para se inserir em brechas de mercado agroalimentar são os circuitos curtos de comercialização de alimentos (CCC), ou mercados de proximidade.

Os CCC podem otimizar a distribuição, o transporte, a gestão das vendas e a identificação entre produtores e consumidores. Eles envolvem operações comerciais que reduzem a distância entre o local da produção e de consumo, além de aproximar relacionalmente quem produz de quem consume. Eles favorecem a segurança alimentar, na medida em que a proximidade facilita a venda de produtos frescos e diversificados, fomentando a agricultura familiar, ao mesmo tempo em que promovem a recuperaçãodo cultivo de espécies locais. Segundo Darolt (2013), os agricultores vinculados ao CCC geralmente contam com sistemas de produção diversificados. A diversificação dos agroecossistemas, por sua vez, é apontada por Altieri e Nicholls (2005) como elemento-chave para organizar sistemas produtivos agroecológicos. Entretanto, a configuração de novos CCC exige organizar relações comerciais, de confiança e logísticas que não são facilmente operadas pelos agricultores e suas organizações.

Considerando os elementos acima, estudamos os processos de comercialização de uma rede de cooperativas, a qual propõe a agroecologia como abordagem central em suas dinâmicas produtivas e comerciais. Trata-se de uma rede de cooperativas de agricultores assentados, composta por 14 organizações de reforma agrária do Estado do Paranál Brasil. O artigo analisa a diversidade de produtos envolvidos em seus processos de comercialização e a proximidade/distância dos circuitos comerciais operados. O objetivo é verificar a compatibilidade de seus processos de comercialização com o princípio agroecológico da diversificação e com a abordagem dos CCC, identificando se as dinâmicas comerciais induzem a uma convencionalização da agricultura orgânica. A convencionalização é entendida como um processo de redução de valores e práticas agroecológicos a procedimentos similares aos encontrados na produção e no mercado convencional de alimentos (Canuto, 2001; Guthman, 2004; Niederle \& Almeida, 2013).

Além desta introdução, o artigo apresenta uma rápida contextualização dos sistemas hegemônicos de comercialização de alimentos, seguida de uma reflexão sobre a incipiente produção bibliográfica em torno dos processos comerciais agroecológicos. 
Sobre estes, dá maior enfoque aos denominados circuitos curtos de comercialização de alimentos, apontados como componentes-chave de uma abordagem agroecológica. A seguir, apresenta a metodologia da pesquisa realizada junto à rede de cooperativas, a qual é seguida dos resultados e discussões e das conclusões do estudo.

\section{Especialização e circuitos longos de comercialização: formas dominantes de mercados agroalimentares}

Sistemas alimentares centrados na agricultura familiar estão perdendo espaço em consequência do avanço da agricultura industrial, produzida em monoculturas, que depende de grandes extensões de terra, do uso intenso da mecanização, do alto consumo de água e de combustíveis, do emprego de fertilizantes químicos, sementes transgênicas, agrotóxicos e antibióticos (Brasil, 2014). De acordo com Altieri (2012), calcula-se que os custos ambientais (impactos sobre a fauna, polinizadores, inimigos naturais, pesca, água e o desenvolvimento de resistência) e sociais (envenenamento e doenças) do uso de agrotóxicos atinjam cerca de US\$ 8 bilhões por ano. Preocupa saber que o consumo de agrotóxicos está aumentando e que o Brasil ocupa o posto de maior consumidor mundial (Niederle \& Almeida, 2013).

A agricultura, como processo produtivo, é uma atividade humana que simplifica a natureza. Entretanto, as monoculturas levam esta simplificação ao extremo. A especialização tem contribuído para a redução da diversidade produtiva de alimentos, gerando uma homogeneização dos agroecossistemas. Machado e Filho (2014) afirmam que, atualmente, 15 espécies respondem por $90 \%$ dos alimentos vegetais e quatro culturas - milho, trigo, arroz e soja - respondem por $70 \%$ da produção e do consumo mundial. Sobre esta especialização, Altieri (2012) afirma que, em todo o mundo, 91\% do 1,5 bilhão de hectares de terras cultiváveis são produzidos principalmente em monoculturas de trigo, arroz, milho, algodão e soja. Salienta que o principal problema das monoculturas é o aumento da vulnerabilidade dos cultivos às pragas e doenças, o que exige grandes quantidades de agrotóxicos, que são cada vez menos eficazes e que acarretam custos ambientais e humanos consideráveis. Para Machado e Filho (2014), a produção biodiversa é a forma de assegurar o indispensável estado dinâmico da heterogeneidade da natureza.

Bezerra e Schneider (2012) destacam a existência de uma relação direta e simbiótica da agricultura com a indústria de alimentos, orientada pelo interesse no lucro. Segundo Altieri (2012), esta orientação induz à busca por uma produção máxima, a qualquer custo, e não a uma produção ótima, que respeite as dinâmicas dos agroecossistemas, como propõe a abordagem agroecológica. A relação simbiótica entre agricultura e indústria alimentícia vem ocasionando a ruptura espacial e temporal da produção e do acesso aos alimentos. Isto se deve às possibilidades tecnológicas de produção de alimentos em larga escala, à sua conservação por longo tempo e à viabilidade global de transporte e negociação (Proença, 2010).

Os sistemas de comercialização a longas distâncias permitem, de um lado, um acesso a diferentes produtos para consumidores de diferentes locais (Popkin, 2009), porém, de outro lado, tal acesso é normalmente por meio de produtos industrializados, com forte carga de aditivos químicos e com impacto na redução da base produtiva alimentar de diferentes locais. Este processo provoca mudanças nos padrões de alimentação na maioria dos países. Essas mudanças, segundo Brasil (2014), envolvem 
a substituição de alimentos in natura ou minimamente processados, de origem vegetal (arroz, feijão, mandioca, batata, legumes, verduras) e preparações culinárias à base desses alimentos, por produtos industrializados prontos para o consumo.

Os circuitos longos de comercialização de alimentos permitem que intermediários se beneficiem da maior parte do valor gerado com a comercialização. No Brasil, de acordo com Junior et al. (2003), são os grandes agentes que têm ficado com a maior parte do valor gerado nos circuitos de venda de alimentos. Estes circuitos longos estão também associados a um maior custo energético, especialmente devido ao consumo de combustíveis de origem fóssil em viagens de longa distância, com efeito negativo sobre o meio ambiente e na saúde da população. Também, quanto maior o deslocamento dos alimentos, maiores são as perdas e o desperdício de alimentos (Brasil, 2014). De acordo com a FAO (Food and Agriculture Organization of the United Nations), a soma de perdas e o desperdício de alimentos, anualmente, contabilizam a quantia de 1,3 bilhão de toneladas no mundo, com impactos negativos sobre o clima, a água, a terra e a biodiversidade. Deste total, estimou-se que 54\% ocorrem na fase inicial da produção, manipulação, pós-colheita e armazenagem, enquanto $46 \%$ ocorrem nas etapas de processamento, distribuição e consumo (FAO, 2013).

As grandes redes de supermercados representam um dos elos mais importantes dos circuitos longos de comercialização de alimentos (Guivant et al., 2010). Elas contribuem neste processo de maior deslocamento dos alimentos. A título de exemplo, Sato (2009) disserta que a rede Carrefour, gigante do varejo agroalimentar, possui um centro de distribuição de alimentos, em São Paulo, que atende mais de 50 milhões de consumidores. Essa rede adquire melões de três produtores do Nordeste para abastecer suas lojas brasileiras e envia a fruta para outros centros de distribuição em 21 países. Portanto, trata-se de um caso típico de especialização e centralização no processo comercial, desenvolvido na lógica de circuitos longos de comercialização. Sato (2009) destaca outro exemplo na Tailândia (Ásia), onde um grande supermercado reduziu sua lista de fornecedores de 250 para 10, o que representa um forte processo de especialização, com concentração territorial e comercial.

Em face disso, Flexor (2006) aponta que os impactos sociais e econômicos deste sistema são dramáticos, especialmente para os agricultores menos capitalizados. Em consequência, tem-se um movimento acelerado no sentido de sistemas de produção e comercialização que reduzem o número de produtores, na medida em que aumentam a especialização, a intensidade de capital e a escala (Perez-Cassarino \& Ferreira, 2013; Goodman et al., 2008).

Estas formas dominantes de produção e mercado agroalimentar vêm sendo alvo de muitas críticas, de um lado, pelas externalidades sociais e econômicas evidenciadas na exclusãode ampla base social da produção de alimentos e, de outro, pelos questionamentos acerca da degradação ambiental e dos impactos à saúde dos consumidores e produtores destes alimentos. Em face disso, têm ganhado força as abordagens que apontam para redes agroalimentares alternativas, seja no campo da produção, distribuição ou do consumo, muitas das quais se articulam em torno da abordagem agroecológica.

\section{Agroecologia, mercados de alimentos e agricultores familiares}

Os questionamentos acerca do modelo dominante de produção e consumo alimentar levaram 
diferentes grupos sociais a promover mudanças significativas nos sistemas de produção e consumo. Muitos destes grupos se organizam com vistas à construção de uma democracia agroalimentar (Pascucci, 2010; Lamine et al., 2012; Renting et al., 2012), buscando produção e acesso a produtos de qualidade. Niederle e Almeida (2013) apontam que uma das mudanças mais evidentes diz respeito às agriculturas de base ecológica, envolvendo um amplo conjunto de formas de produção que se estruturam a partir da agroecologia. A agroecologia, assim, torna-se um componente-chave para a construção de redes agroalimentares alternativas. Para Perez-Cassarino et al. (2013), ela gera condições para o enfrentamento dos padrões hegemônicos do sistema agroalimentar.

Na perspectiva agroecológica, a produção diversificada é chave, pois desde os estudos de Darwin sabe-se que os ecossistemas mais estáveis (resilientes a eventos externos) são aqueles mais diversificados e complexos. Isto exige processos comerciais apropriados, que priorizem o abastecimento dos mercados locais, que encurtem as distâncias entre a produção e o consumo de alimentos, permitindo a produção e a comercialização diversificadas, evitando assim o desperdício de energia gasta no transporte dos produtos (Altieri, 2012).

A diversificação produtiva é elemento-chave para a sustentabilidade ambiental, a qual também é uma importante fonte de renda para os agricultores, visto que se trata de alimentos básicos utilizados na alimentação humana, fundamentais para a promoção de saúde e qualidade de vida. Para Brasil (2014), alimentos in natura ou minimamente processados, em grande variedade e predominantemente de origem vegetal, são a base de uma alimentação nutricionalmente balanceada, saborosa, culturalmente apropriada e promotora de um sistema alimentar social e ambientalmente sus- tentável. Por razões sociais, econômicas e de saúde, a diversificação produtiva é importante. Ademais, é destacada sua importância como estratégia para a preservação de variedades vegetais adaptadas às diferentes regiões do planeta.

A produção diversificada exige a construção de circuitos comerciais que a viabilizem. Neste sentido, os mercados de proximidade ou circuitos curtos de comercialização (CCC) de alimentos implicam em facilidades de distribuição, transporte, gestão das vendas e maior identificação entre produtores e consumidores, além de uma opção ideológica contrária aos circuitos longos, representativos da agricultura convencional (Comunello, 2010). Eles envolvem operações comerciais que reduzem a distância entre oslocais da produção e de consumo, além de aproximar relacionalmente quem produz de quem consome.

O conceito de circuito curto de comercialização de alimentos, conforme apontado por Darolt et al. (2013), é utilizado na França para caracterizar os circuitos de distribuição que mobilizam até, no máximo, um intermediário entre produtor e consumidor, assim como uma distância de até $80 \mathrm{~km}$. Entretanto, a ênfase dos franceses e outros europeus se dá na proximidade relacional do processo comercial (até um intermediário), e não na proximidade espacial. Os referidos autores apontam a existência de duas principais modalidades de circuitos curtos, sendo a venda direta e a venda indireta.

A venda direta envolve relação direta entre produtor e consumidor, por meio de ações dentro e/ou fora das propriedades rurais. A venda indireta é aquela em que ocorre a intervenção de um único intermediário entre produtor e consumidor. Ela é realizada por meio de lojas especializadas, lojas de cooperativas de produtores e consumidores, restaurantes coletivos, pequenos mercados de produtos naturais (orgânico e convencional) e lojas virtuais 
(compra por internet). Há também os mercados institucionais, que podem operar formas de venda direta ou indireta, a depender se a compra se dá entre a organização de agricultores e o ponto de consumo, ou se haveria outros intermediários no meio. Nestas formas de mercado, um ente do Estado compra os alimentos para repassá-los a entidades sociais, restaurantes escolares, etc.

Os mercados de proximidade prezam pelo fortalecimento das relações entre produtores e consumidores, com operações comerciais no território local, sem ou com pouca presença de intermediários. Estes circuitos, segundo Darolt (2013), realçam princípios como: autonomia, solidariedade, segurança alimentar, justiça social, respeito à cultura e tradições locais. O mesmo autor aponta que agricultores vinculados a circuitos curtos de produção e consumo de alimentos, no Brasil, geralmente contam com sistemas de produção diversificados e trabalham simultaneamente com sistemas vegetais e animais integrados.

Para Bezerra e Schneider (2012), a circulação, seja na produção ou no consumo de alimentos no âmbito local, potencializa, também, outras relações sociais, econômicas e alimentares que vão além da "simples" resistência ao processo de desconexão do sistema agroalimentar hegemônico. Santos et al. (2009) salientam que a distribuição de alimentos, geralmente na forma de comercialização direta, tem gerado experiências que resgatam a histórica relação entre comunidades rurais e agrupamentos urbanos próximos, recuperando assim a cooperação entre diferentes grupos e atividades humanas.
Dois Programas Institucionais têm ganhado notória relevância no fortalecimento dos circuitos locais de produção e consumo de alimentos. Um deles é o Programa Nacional de Alimentação Escolar (PNAE), que coloca a exigência de que $30 \%$ da alimentação escolar seja comprada da agricultura familiar, dando preferência aos produtores locais, conforme estabelece a Lei $\mathrm{n}^{\mathrm{o}} 11.947$, de 16 de junho de 2009. Outro é o Programa de Aquisição de Alimentos (PAA) ${ }^{1}$, cujo propósito é promover o acesso à alimentação para pessoas em situação de insegurança alimentar e nutricional, atendidas por programas sociais, com a compra de produtos da agricultura familiar. Este programa foi instituído pelo art. 19 da Lei n ${ }^{\circ} 10.696$, de 02 de julho de 2003.

Estes dois programas, nos últimos anos, se destacaram na compra de produtos de base ecológica. Tais produtos recebem um preço Premium $30 \%$ superior ao produto similar da agricultura convencional. O mercado institucional reforça iniciativas de comercialização em circuitos curtos, pela prioridade que dão aos produtos da região onde ocorrerá o consumo dos alimentos, bem como fortalecem as redes organizacionais e o diálogo entre os atores envolvidos com a agroecologia (Darolt, 2013; Bezerra \& Schneider, 2012). Tais programas e os circuitos curtos de comercialização por eles estimulados contribuem com um processo de relocalização da produção e do consumo alimentar. Para Schmitt (2011), em vez da comida de nenhum lugar, cultivada por produtores desconhecidos, embalada e transportada em longas distâncias por grandes corporações, ganham visibilidade outras práticas,

\footnotetext{
${ }^{1}$ O Programa de Aquisição de Alimentos - PAA - foi instituído pelo art. 19 da Lei n ${ }^{\circ} 10.696$, de 02 de julho de 2003. Ele promove a aquisição de alimentos diretamente de agricultores familiares, ou por meio de suas associações/cooperativas, com dispensa de licitação, destinando-os à formação de estoques governamentais ou à doação para pessoas em situação de insegurança alimentar e nutricional, atendidas por programas sociais. Este programa é implantado em cinco modalidades, em parceria com a Companhia Nacional de Abastecimento (Conab), governos estaduais e municipais (Brasil, 2014).
} 
antigas, novas ou renovadas. São práticas sinalizadoras de um jeito diferente de produzir, distribuir, escolher, valorizar e consumir os alimentos, dentro do que propõe a agroecologia.

Maluf (2004) advoga que a promoção dos pequenos produtores de alimentos estimula a equidade e a inclusão social, em simultâneo a uma maior e mais diversificada oferta de alimentos à população, produzidos sob formas sustentáveis. A produção de alimentos a partir de formas sustentáveis torna-se cada vez mais necessária, em face da crescente demanda por alimentos e da crise ambiental global, o que remete a um apelo por práticas que minimizem impactos ambientais, mas que possam assegurar a produção de alimentos em quantidades suficientes para atender as necessidades de alimentação, sem comprometer a capacidade produtiva dos agroecossistemas.

O fortalecimento dos circuitos curtos de comercialização dialoga com a segurança alimentar, fomenta a agricultura familiar, ao mesmo tempo em que promove a recuperação do cultivo de espécies locais e proporciona redução das distâncias a serem percorridas pelos alimentos entre o local da produção e o local do consumo. Nesta perspectiva, Schmitt (2011) salienta que é preciso estimular as ligações entre os sistemas diversificados da agricultura familiar e a preservação, in situ, da biodiversidade agrícola e alimentar, fundamental para a manutenção e o fortalecimento da capacidade de produzir alimentos em um cenário marcado por mudanças climáticas de alcance global.

Ademais, segundo Schmitt (2011), a estruturação dos mercados locais, como um componente na construção de estratégias sustentáveis de desenvolvimento rural, não se traduz necessariamente em um localismo defensivo, ou seja, uma defesa irrefletida dos produtos e dos circuitos locais sem considerar as complexas relações que se estabelecem entre o local e o global. Deste modo, na perspectiva de assegurar a preservação da diversidade produtiva, a qual é princípio-chave da abordagem agroecológica, a qualificação e a ampliação de mercados de proximidade são elementos centrais, visto que estes valorizam produtos locais e regionais (Proença, 2010) e contribuem para o resgate da histórica relação entre comunidades rurais e agrupamentos urbanos, bem como a soberania e segurança alimen$\operatorname{tar}$ (Bezerra \& Schneider, 2012; Santos et al., 2009).

Entretanto, a disseminação dos alimentos orgânicos em muitos países tem provocado uma inquietação quanto a uma convencionalização da produção orgânica. Tal preocupação foi inicialmente evidenciada em estudos da década de 1990, de Buck, Gets e Guthman, nos Estados Unidos, e traz uma apreensão com o enfraquecimento dos princípios agroecológicos perante lógicas próprias do mercado e a concorrência com as agrobusiness firms (Guthman, 2004). Isto significaria uma pressão sobre as unidades de produção orgânica para se especializarem e ampliarem a escala, gerando dependência de insumos e canais de comercialização, muito semelhante às formas convencionais de agricultura. Consideramos, neste artigo, que a diversidade de produtos comercializados e a distância da produção até a venda no varejo são importantes expressões do maior ou menor risco de convencionalização da produção.

\section{Metodologia e procedimentos metodológicos}

Estudamos uma rede de cooperativas de agricultores assentados, composta por 14 cooperativas de reforma agrária do Estado do Paraná/Brasil. Esta rede defende a agroecologia como abordagem central em suas dinâmicas produtivas e comerciais. Trabalhamos com a análise de duas categorias que 
permitem verificar a identidade dos processos comerciais com a agroecologia: a diversidade de produtos envolvidos nos processos de produção e comercialização, e a proximidade/distância dos circuitos comerciais operados. Além destas duas categorias postas para a análise, e a partir delas, verificamos o grau de autonomia de agricultores e das cooperativas nos processos produtivos e comerciais, a partir das implicações/determinações das operações mercantis.

A categoria "diversidade" foi analisada a partir da maior ou menor presença de produtos alimentícios nos processos comerciais, evidenciando como as cooperativas organizam a produção junto a sua base social e econômica. Aqui, nosso olhar analítico recai sobre a diversidade versus a restrição de produtos comercializados (especialização), visto a diversidade produtiva ser elemento central da abordagem agroecológica.

A categoria "proximidade/distância dos mercados" foi analisada a partir da distribuição espacial dos alimentos comercializados, tendo como referência as discussões acerca da distinção entre circuitos curtos e longos de comercialização. Aqui tem força a relação estabelecida pela bibliografia entre os CCC e a abordagem agroecológica, sobretudo no que se refere às discussões acerca da importância da relocalização da produção e do consumo de alimentos.

Os procedimentos utilizados para a coleta e análise de dados compreendem a análise de documentos comerciais e gerais das 14 cooperativas; entrevistas com dirigentes utilizando-se da técnica do grupo focal ${ }^{2}$, de modo que em cada cooperativa participaram da entrevista duas ou mais pessoas de notório conhecimento sobre os processos comerciais da mesma; além da observação não participante junto às dinâmicas comerciais operadas. $\mathrm{O}$ trabalho de campo foi iniciado no mês de maio de 2013 e foi concluído em abril de 2015. Os dados quantitativos foram coletados no primeiro semestre do ano 2014.

A partir da análise dos documentos comerciais e gerais das cooperativas, foram sistematizados os dados quantitativos sobre as vendas, referentes ao ano fiscal 2012/2013. Com base nesta sistematização, a partir da diversidade de produtos e da distância entre produção e consumo, identificamos elementos que permitiram distribuir as 14 cooperativas em 03 grupos, os quais expressam uma maior ou menor aproximação com a abordagem agroecológica. Estes grupos foram identificados com as letras $A, B$ e $C$. O grupo $A$ é composto por cinco cooperativas e é considerado o mais próximo da abordagem agroecológica. As cooperativas que o integram comercializam ampla diversidade de produtos e a maior proporção de sua produção é realizada em sistemas agroecológicos e orgânicos ${ }^{3}$. Sua comercialização é predominantemente realizada no mercado regional (até $80 \mathrm{~km}$ ), em operações comerciais diretas e indiretas que aproximam produtores e consumidores. $O$ grupo $B$ é composto por quatro cooperativas que comercializam elevada di-

\footnotetext{
${ }^{2}$ De acordo com Gondim (2002), o grupo focal representa uma fonte que intensifica o acesso às informações acerca de um fenômeno, seja pela possibilidade de gerar novas concepções ou pela análise e problematização em profundidade de uma ideia. Ele contrasta, nesse sentido, com dados colhidos por meio de questionários ou entrevistas individualizadas, nos quais o participante é convocado a emitir opiniões sobre assuntos, sem contraposições e interfaces com outros participantes.

${ }^{3}$ Fazemos referência a produtos orgânicos e agroecológicos porque há casos, nas cooperativas estudadas, nos quais os produtos são devidamente certificados como orgânicos, enquanto há outros nos quais isto não ocorre, mesmo que em todos os casos não haja uso de agrotóxicos, adubos e outros produtos de síntese química. Optamos por evidenciar esta diferença, na medida em que para aqueles definidos como agroecológicos faltaria apenas avançar com a certificação orgânica de seus produtos para vendê-los como tal.
} 
versidade de produtos, porém, a maior proporção da produção ocorre em sistemas convencionais ${ }^{4}$. Sua comercialização é realizada tanto no mercado regional (até $80 \mathrm{~km}$ ), que é o principal consumidor da sua diversidade de alimentos, quanto em circuitos longos de comercialização, muito embora boa parte das vendas se refira ao mercado institucional e a cooperativas da mesma rede. $O$ grupo $C$ é composto por cinco cooperativas que comercializam limitada diversidade produtiva, cuja produção ocorre com grande predominância em sistemas de produção convencionais. A produção dos agricultores a elas vinculados está atrelada a processos agroindustriais que dão origem a alimentos industrializados, cuja comercialização é realizada tanto no mercado regional (até $80 \mathrm{~km}$ ) quanto em circuitos longos.

As entrevistas foram realizadas com líderes de 07 cooperativas, sendo 02 do grupo $A, 02$ do grupo $B$ e 03 do grupo $C$, ao longo do segundo semestre de 2014. Seu objetivo foi aprofundar informações e esclarecer possíveis dúvidas quanto ao perfil das cooperativas e dos diferentes grupos tipificados pelos pesquisadores. Os dados foram organizados em planilhas do Excel 97X2003. A pesquisa foi aprovada pelo Comitê de Ética em Pesquisa da Universidade Federal de Santa Catarina - UFSC, sob o parecer de $\mathrm{n}^{0} 746.576$.

\section{A Rede de Cooperativas de Reforma Agrária do Paraná e a agroecologia}

Esta seção apresenta dados do estudo a campo realizado junto à Rede de Cooperativas da Reforma Agrária do Paraná, discutindo elementos que demonstram a (in)compatibilidade de suas práticas comerciais com a diversificação comercial/produtiva e a abordagem dos CCC. Compreendemos que isto poderá indicar maior ou menor aproximação com a perspectiva agroecológica e identificar riscos de convencionalização deste processo.

\subsection{Diversificação produtiva ou especialização?}

As cooperativas que formam a rede estudada se diferem em relação a muitos fatores. Um deles está relacionado diretamente com a diversidade de produtos produzidos pelos seus associados e por elas comercializados. Na Figura 1, podemos ver uma nítida distinção entre elas, configurando dois agrupamentos, um que comercializa pequena diversidade de produtos, abaixo de 12, enquanto há outro grupo que comercializa acima de 46 produtos por cooperativa.

Esta diferença revela formas variadas de desenvolvimento das cooperativas e de como cada uma orienta seus produtores vinculados, no que se refere ao esforço da organização em auxiliar na comercialização da diversidade de produtos de seus associados. Verificamos um conjunto de cinco cooperativas (itens J até N na Figura 1) que comercializa uma média de 06 (seis) tipos de produtos, especialmente industrializados, como arroz, leite e derivados, erva-mate e café. Essas organizações têm uma idade média de 18,6 anos de existência e sua atuação tem foco principal na comercialização de produtos alimentícios provenientes das cadeias de produção amplamente desenvolvidas pelas fa-

\footnotetext{
${ }^{4}$ Neste estudo, optamos por analisar o destino de toda produção das cooperativas e não apenas dos seus produtos orgânicos/agroecológicos. Isto porque toda a rede de cooperativas estudada propõe a agroecologia como central para sua atuação produtiva e comercial. Assim, para melhor entender sua compatibilidade a este objetivo, avaliamos ser adequado explicitar e analisar todos os seus produtos.
} 


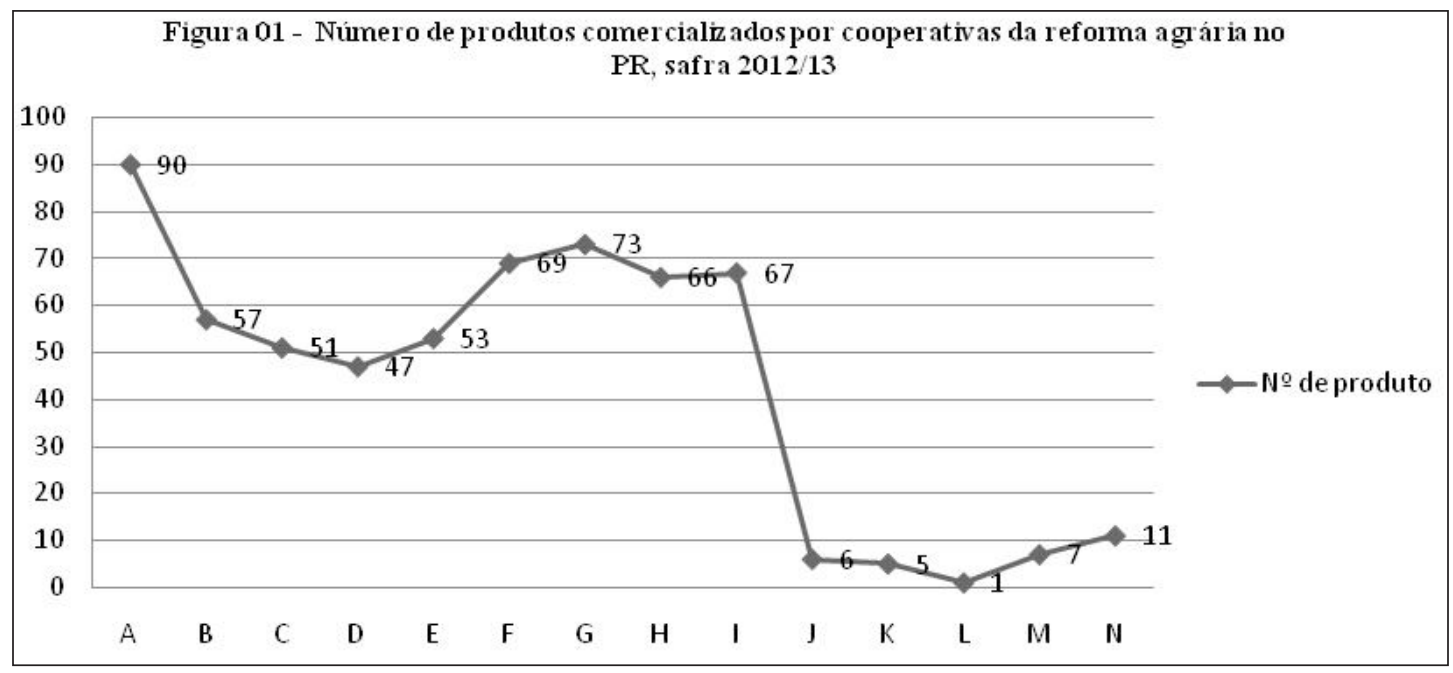

FIGURA 1 - Número de produtos comercializados por cooperativas da reforma agrária no PR, safra 2012/13.

Eixo y: expressa o número de produtos; Eixo x: representa as cooperativas identificadas com letras de a/n.

FONTE: Pesquisa de Campo.

mílias associadas. Observamos que este grupo de cooperativas se insere numa trajetória que investiu em plantas agroindustriais e processos comerciais aos quais está vinculado hoje e que dificultam sua efetiva mobilização para ampliar a diversidade produtiva e comercial. Há uma correlação entre o tempo de existência deste grupo de cooperativas e o investimento em plantas industriais maiores, assim como maior especialização em poucos produtos, de cadeias produtivas definidas. Isto revela duas questões: de um lado, podemos falar em um perfil de orientação organizativa, dado pelo Movimento dos Trabalhadores Rurais Sem Terra (MST), ao qual este grupo de cooperativas está vinculado, que na sua origem e até pouco tempo enfatizava a organização deste perfil de organização cooperativa e industrial; de outro, políticas públicas, como o PAA e o PNAE, que estimulam a venda de produtos diversificados, têm pouco mais de uma década de existência e não foram fatores de organização diferencial deste grupo de cooperativas, tendo importância na comercialização da diversidade de produtos do outro grupo de cooperativas (itens A até I da Figura1). Como veremos adiante, os mercados institucionais são importantes também para o grupo das cooperativas dos itens $\mathrm{J}$ até $\mathrm{N}$ na Figura 1, porém não para a venda de alimentos orgânicos/ agroecológicos. A estes dois fatores poderíamos agregar, ainda, a crescente demanda, nos anos recentes, por alimentos orgânicos/agroecológicos.

As cooperativas dos itens $\mathrm{J}$ até $\mathrm{N}$ da Figura 1 avançaram nas cadeias de produção citadas em função de seu vínculo territorial, na medida em que estas cadeias já possuíam um histórico de construção nas regiões em que as cooperativas e os assentamentos se sediaram. Vinculadas a uma trajetória territorial, elas demonstraram baixa capacidade de se organizar para outras cadeias de produção e para estimular maior diversidade produtiva de seus produtores.

Nos itens A até I da Figura 1, há nove cooperativas que comercializam ampla diversidade 
de alimentos, especialmente na forma in natura, com uma média de 63,7 tipos de produtos por cooperativa. Os principais produtos comercializados são frutas cítricas, legumes, verduras, tubérculos, sementes de milho crioulo e panificados. Estas 09 organizações têm uma idade média de 6,77 anos de existência. Elas promovem a diversificação produtiva nas unidades de produção familiar, por meio da criação de oportunidades de venda. $\mathrm{O}$ fato de serem cooperativas jovens ajuda a explicar sua maior diversificação produtiva e comercial, considerando a recente valorização dos produtos orgânicos/agroecológicos e o advento dos mercados institucionais originados do PAA e do PNAE.

Observamos que a estratégia comercial de muitas cooperativas, especialmente aquelas que comercializam ampla diversidade de alimentos, permite aos produtores associados organizar a produção no sistema de policultura, com o cultivo de diversas culturas agrícolas (milho, feijão, arroz, tubérculos, legumes, verduras, frutíferas, etc.), normalmente combinadas com a bovinocultura de leite, o que permite diversificar os processos produtivos e a renda agrícola das famílias. Isto gera uma maior autonomia dos produtores/as em relação aos mercados, onde os agricultores e suas organizações devem estar atentos às demandas dos consumidores, organizando-se para atendê-las, sem ter sua base produtiva definida, a priori, por empresas fora de seu escopo organizativo. Assim, as definições sobre o que, quando e como produzir são negociadas considerando as condições agroecossistêmicas, os elementos de sazonalidade e o perfil dos produtores, sem desconsiderar os sinais da demanda por produtos. Desta forma, gera-se também a redução de custos para os agricultores, decorrente de maior produção para o autoabastecimento e menos gastos na compra de gêneros alimentícios.
O contrário ocorre nas cooperativas que atuam com a comercialização de limitada diversidade de alimentos, que, ao não criar oportunidades de venda para outros tipos de produtos da agricultura familiar, promovem a especialização produtiva nas unidades de produção. Acreditamos que seja possível e necessário algum grau de especialização dos processos produtivos e comerciais, mas que isto não precisa, necessariamente, quebrar com um grau adequado de diversidade produtiva. O desafio estaria em encontrar escalas ótimas, para cada contexto e produtos, que otimizassem custos de logística e organização, mas não representassem estímulo à restrição da base produtiva e comercial.

A diversidade produtiva nas unidades de produção familiar permite que produtores e consumidores se beneficiem mutuamente. Os primeiros têm a vocação, a profissão escolhida ou a que lhe restou devido à ausência de outra oportunidade, mas que precisam produzir e comercializar os alimentos como forma de garantir as condições necessárias à sua reprodução social no campo. Os últimos precisam se alimentar, o que pressupõe a ingestão de alimentos saudáveis e diversificados, em atendimento às necessidades alimentares, que também auxiliam na promoção de saúde e qualidade de vida.

A diversidade produtiva é essencial na agroecologia, a qual também é uma das principais características da agricultura familiar e pode ser uma importante fonte de renda para os agricultores, ao mesmo tempo em que importantes serviços ambientais são prestados, a exemplo da conservação da biodiversidade, a preservação dos mananciais hídricos, a preservação da beleza cênica e o sequestro de carbono. Para fazer da diversificação produtiva uma fonte de renda para os agricultores familiares residentes em regiões distantes de centros urbanos, no entanto, é necessário o enfrentamento das condições que se apresentam como barreiras à comer- 
cialização. Isto exigiria desde a melhor estruturação dos processos produtivos no campo, iniciando ali a agregação de valor mediante certificação orgânica, passando pelo beneficiamento mínimo e/ou agroindustrialização, articulação entre ganhos de escala e escopo produtivo, além da redução de custos operacionais produtivos e comerciais. $\mathrm{O}$ investimento em alimentos agroecológicos, coloniais e outras características diferenciais vai ao encontro do desejo dos consumidores finais, que procuram benefícios à sua saúde individual e familiar. Além disto, reforçar mercados como o PAA e o PNAE e criar outras políticas de incentivo à diversificação poderia estimular mais produtores e cooperativas, gerando um ciclo virtuoso que priorizasse a diversidade produtiva e organizasse processos comerciais que estimulassem esta abordagem.

\subsection{Da produção ao consumo final: quais mercados de proximidade?}

O conjunto das cooperativas estudadas comercializou aproximadamente 19.219 toneladas de alimentos no ano estudado. Deste total, quase $69 \%$, o que corresponde a aproximadamente 13.243 toneladas, foram destinadas ao mercado institucional (PAA, PNAE, Programa Leite das Crianças do Governo do Paraná ${ }^{5}$ - ( (Figura 2).

Neste estudo, consideramos mercados de proximidade aqueles cujas operações comerciais foram realizadas em um raio até 100 quilômetros distantes do local da produção. Além disto, consideramos a presença de no máximo um intermediário nas operações comerciais, sem considerar como inter- mediário a cooperativa que representa os agricultores. Da mesma forma, estamos considerando como circuitos longos de comercialização de alimentos (CLC) as operações comerciais realizadas a uma distância superior a $100 \mathrm{~km}$ do local da produção e com envolvimento de mais que um agente intermediário nas operações comerciais. A opção pela quilometragem citada leva em conta a perspectiva agroecológica do mínimo deslocamento possível, mas também amplia aquela proposta pelos europeus, que é de no máximo $80 \mathrm{~km}$ de distância. Num país continental como o Brasil, no qual distâncias dentro de uma mesma região às vezes superam esta quilometragem, há contextos que exigirão seu repensar. Na ausência de estudos mais qualificados sobre esta questão, escolhemos a referência de 100 $\mathrm{km}$ porque ela levaria em conta a realidade estudada e indicaria um raio aproximado no qual cada cooperativa faria sua comercialização dentro da sua própria região de atuação. Assim, os parâmetros aqui adotados podem não ser válidos para outros estudos, visto que o conceito de circuitos curtos de comercialização de alimentos no Brasil encontra-se em construção.

Ao estudarmos as 14 cooperativas, a partir da diversidade de produtos e da distância entre produção e consumo, identificamos elementos que permitiram distribuí-las em 03 grupos, os quais expressam uma maior e/ou menor aproximação com a abordagem agroecológica. Estes grupos foram identificados com as letras $A, B$ e $C$.O grupo $A$ é considerado o mais próximo da abordagem agroecológica, o grupo $B$ é considerado intermediário e o grupo $C$ é o mais distante da abordagem agroe-

\footnotetext{
${ }^{5}$ O Programa Leite das Crianças - PLC - atende a todos os 399 municípios do Estado do Paraná. Tem por objetivo auxiliar o combate à desnutrição infantil, por meio da distribuição gratuita e diária de um litro de leite às crianças de 06 a 36 meses, pertencentes a famílias cuja per capita não ultrapassa meio salário mínimo regional, além do fomento à agricultura familiar. (Brasil, 2015).
} 


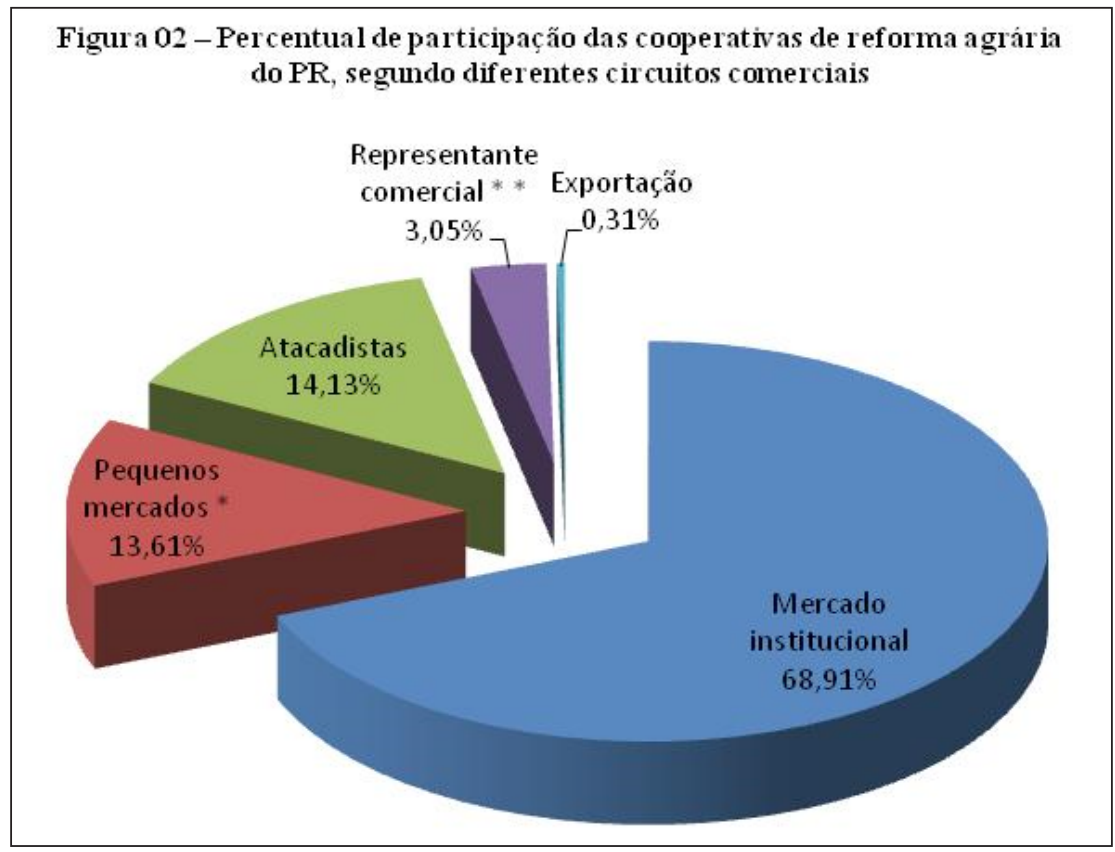

FIGURA 2 - Percentual de participação das cooperativas de reforma agrária do PR, segundo diferentes circuitos comerciais.

*Denominamos de pequenos mercados as diversas modalidades de comercialização de alimentos, dentre elas: feiras, venda domiciliar, lojas de produtos naturais orgânicos e convencionais, mercados de bairro, restaurantes, etc.

${ }^{* *}$ Representante comercial: trata-se de pessoa física ou jurídica que realiza a venda de alimentos em estabelecimento comercial próprio e/oufaz a redistribuição a outros estabelecimentos comerciais.

FONTE: Pesquisa de campo.

cológica. Esse agrupamento permite analisar com mais precisão como é o processo de inserção das cooperativas nos mercados de alimentos, bem como para quais canais de comercialização estão sendo destinados os alimentos orgânicos/agroecológicos e convencionais, conforme demonstraremos a seguir. A Figura 3 apresenta o percentual de volume de alimentos das cooperativas que percorreram diferentes quilometragens, no exercício fiscal 2012/13.

Podemos observar, na Figura 3, que o mercado regional (até $100 \mathrm{~km}$ ) absorveu $37,03 \%$ do volume total de alimentos comercializados. Isto corresponde a aproximadamente 7.116 toneladas de alimentos. Ao analisarmos a inserção dos grupos de cooperativas neste circuito comercial, constatamos que o mesmo absorveu $99,97 \%$ dos alimentos comercializados pelas cooperativas que formam o grupo $A, 58,43 \%$ dos alimentos comercializados pelas cooperativas que formam o grupo $B$ e $21,55 \%$ dos alimentos comercializados pelas cooperativas que formam o grupo $C$.

Também merece destaque, na Figura 3, que $52 \%$ do total comercializado pelas cooperativas se dá num raio até $200 \mathrm{~km}$. Considerando a realidade brasileira, isto revela que a maioria delas, mesmo estando fora do que denominamos de circuitos cur- 


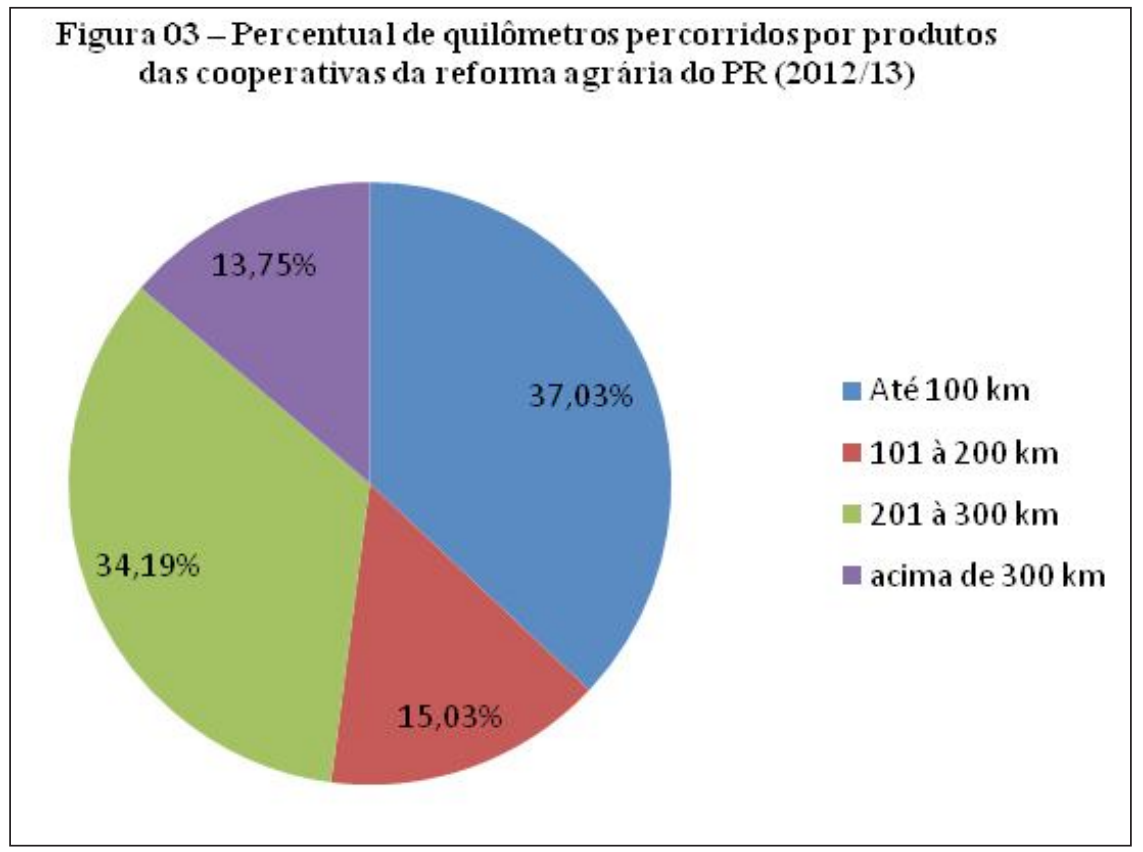

FIGURA 3 - Percentual de quilômetros percorridos por produtos das cooperativas da reforma agrária do Paraná (2012/13).

FONTE: Pesquisa de campo.

tos de comercialização, ainda assim comercializa a distâncias que não poderiam ser denominadas de circuitos longos. A maioria destas vendas até $200 \mathrm{~km}$ é feita diretamente aos consumidores, aos pontos de consumo ou com no máximo um intermediário entre produtores e consumidores. Ou seja, mesmo que os circuitos pudessem ser considerados longos do ponto de vista espacial, são curtos do ponto de vista relacional, ou do número de intermediários.

O grupo $A$, considerado o mais próximo de uma abordagem agroecológica, é formado por 05 cooperativas, com idade média de 5,4 anos de existência. Este grupo foi responsável por aproximadamente $7,91 \%$ das vendas realizadas pela rede de cooperativas, o que corresponde a aproximadamente 1.520 toneladas de alimentos. Deste total, $43,71 \%$ ou 664 toneladas de alimentos têm origem em sistemas agroecológicos/orgânicos de produção. Essas cooperativas comercializam uma média de 59,6 tipos de produtos na forma in natura e processados/industrializados, com destaque para hortaliças, frutas, grãos, panificados, produtos de origem animal (mel, leite in natura). Estes alimentos foram destinados ao mercado institucional (PAA, PNAE) e a pequenos mercados (Tabela 1), sendo que o primeiro absorveu $96,39 \%$ e o segundo, $3,31 \%$ do volume total de produtos comercializados ao longo do período citado.

$O$ grupo $B$ é formado por 04 cooperativas, com idade média de 8,5 anos de existência. Elas foram responsáveis por $25,12 \%$ das vendas realizadas pela rede estudada. Isto corresponde a aproximadamente 4.828 toneladas de alimentos, 
TABELA 1 - Quantidade de produtos comercializados (t), em diferentes circuitos comerciais e sistemas de produção, segundo os grupos estudados.

\begin{tabular}{cccccc}
\hline Grupo & Circuito comercial & Orgânico (t)* & Agroecológico (t)** $^{*}$ & Convencional & Totais (ton) \\
\hline \multirow{2}{*}{ A } & Mercado institucional & 267.103 & 377.639 & 821.246 & 1.465 .988 \\
& Pequenos mercados & 23.038 & 12.323 & 19.505 & 54.866 \\
\hline \multirow{2}{*}{ B } & Mercado institucional & 3.614 & 95.040 & 2.027 .510 & 2.126 .164 \\
& Peuquenos mercados & 0 & 0 & 1.660 .912 & 1.660 .912 \\
& Outros *** & 0 & 0 & 1.041 .089 & 1.041 .089 \\
\hline \multirow{2}{*}{ C } & Mercado institucional & 19.127 & 0 & 9.544 .311 & 9.563 .438 \\
& Pequenos mercados & 122.932 & 0 & 864.470 & 987.402 \\
& Outros **** & 51.042 & 0 & 2.269 .055 & 2.320 .097 \\
\hline & Total & $\mathbf{4 8 6 . 8 5 6}$ & $\mathbf{4 8 5 . 0 0 2}$ & $\mathbf{1 8 . 2 4 8 . 0 9 8}$ & $\mathbf{1 9 . 2 1 9 . 9 5 6}$ \\
\hline
\end{tabular}

FONTE: pesquisa de campo.

*Produto orgânico - com certificado.

**Produto agroecológico - sem certificado, porém sem uso de agrotóxicos e aditivos químicos.

*** Atacadistas.

**** Atacadistas, representantes comerciais, exportação.

dos quais apenas 2,04\% têm origem em sistemas agroecológicos/orgânicos de produção. Os alimentos comercializados por este grupo de cooperativas foram destinados a 03 (três) circuitos comerciais (Tabela 1). Podemos ver que o mercado institucional é o principal circuito comercial acessado pelas cooperativas que formam o grupo $B$. Este mercado absorveu aproximadamente $44,04 \%$ dos alimentos, seguido pelos pequenos mercados, com $34,40 \%$, e pelos atacadistas/intermediários, com $21,56 \%$ dos alimentos comercializados. Estes dois últimos canais de comercialização são utilizados para o escoamento de apenas um produto, o leite in natura, que é captado pela cooperativa junto aos associados.

Numa condição mais distante da abordagem agroecológica, encontramos 05 cooperativas que formam o grupo $C$, as quais foram responsáveis por $66,97 \%$ das vendas de alimentos realizadas pela rede no período estudado. Estas organizações comercializam uma média de 06 tipos de produtos alimentícios, com destaque para leite pasteurizado, iogurte, queijos, arroz, café, erva-mate e chás, açúcar mascavo, aguardente. Estes produtos foram destinados a cinco circuitos comerciais, como pode ser observado na Tabela 1 , já que, além dos mercados institucionais e pequenos mercados, comercializam também com atacadistas e representantes comerciais, além da exportação.

Na Tabela 1, podemos ver diversos canais de comercialização em que estas cooperativas participam. No entanto, o mercado institucional é o que mais se destaca pela quantidade de alimentos absorvida (74,30\%). Em seguida, aparecem os atacadistas/intermediários, com $13,02 \%$, pequenos mercados, com 7,68\%, representante comercial, com $4,55 \%$ e, por último, as exportações, que representam $0,45 \%$ do volume total de produtos comercializados por este grupo de cooperativas.

Nos dados apresentados nesta subseção, se evidencia que as cooperativas mais recentes e com menores volumes de produtos comercializam maior diversidade e atingem mais efetivamente os mercados de proximidade. Entendemos que estas evidências não remetem a considerar que para ser agroecológico é necessário ser pequeno, mas que há necessidade de encontrar escalas apropriadas 
de produção e comercialização para diferentes contextos. Muitas organizações que produzem orgânicos/agroecológicos se voltam aos mercados de proximidade e à medida que estes não suportam toda sua oferta, se voltam a mercados mais distantes. Isto indicaria uma complementaridade entre CCC e CLC, orientada pela priorização dos CCC. Entretanto, o que se vê no caso de algumas das cooperativas estudadas é que ainda não houve um efetivo esforço de organizar seus mercados de proximidade. Além disto, está evidente nos dados dos três grupos a importância dos mercados institucionais para viabilidade de suas vendas.

\subsection{O Mercado Institucional: principal circuito comercial das cooperativas de reforma agrária do Paraná}

O mercado institucional gera diversas oportunidades para as organizações da agricultura familiar. Estas oportunidades referem-se às modalidades de venda de alimentos, criadas com o propósito de beneficiar produtores/as e consumidores/as. Se fossem operadas integralmente todas as modalidades possíveis, se avançaria na superação de muitos problemas que limitam a produção e a comercialização de alimentos agroecológicos.

Entretanto, se fossem operadas todas as possibilidades de mercado institucional, não apenas seria aberto um mercado muito maior para a agricultura familiar e para a diversidade produtiva dali advinda, mas certamente faltariam produtos para atender tal demanda numa fase inicial. No entanto, o problema hoje não é de falta de oferta de produtos da agricultura familiar, mas a necessidade de "sensibilizar escola/município/estado para que haja mais compra de alimentos da agricultura familiar [...]" (Cooperativa 06). Outros dirigentes dizem que " [...] somando o PAA, PNAE e Compra Institucional, se torna quase que ilimitado as possibilidades para comercializar, o problema é que na prática não é como na teoria [...]. Em nossas contas, hoje o valor poderia chegar a 60, 70 mil reais por agricultor em vendas ao longo de um ano" (Cooperativa 05).

Uma das principais características dos mercados institucionais é a sua capacidade em absorver ampla diversidade de alimentos. Essa característica dialoga perfeitamente com uma das principais características da agricultura familiar e da abordagem agroecológica, que é a diversificação produtiva. Portanto, estes programas podem elevar o grau de autonomia dos agricultores/as em relação ao que produzir e comercializar, gerando condições para que eles avancem para modos de produção agroecológicos.

As operações comerciais no âmbito dos mercados institucionais fortalecem laços de reciprocidade, confiança, solidariedade, com a identificação entre as partes envolvidas, ao aproximar produtores, organizações sociais e instituições, assim permitindo que mais consumidores e lideranças ligadas a eles compreendam, respeitem e colaborem com as especificidades da produção agropecuária diversificada.

Os mercados institucionais já têm produzido importantes resultados, como relataram diretores de uma cooperativa: "as operações comerciais no âmbito do PAA [...] têm permitido a qualificação crescente dos processos que envolvem a produção e a comercialização [...]". (Cooperativa 05). Eles afirmam, ainda, que estes mercados geram um processo de diálogo, envolvendo organizações dos governos federal, estadual e municipal e organizações do terceiro setor, como, por exemplo, entidades socioassistenciais, hospitais e escolas.

Outra importante característica dos mercados institucionais é que eles contribuem para a 
dinamização da economia local. Como a venda é feita diretamente da cooperativa para as entidades/instituições, maior valor agregado da venda é repassado aos agricultores, sendo que em muitos casos a produção e o consumo ocorrem próximos espacial e relacionalmente. Logo, em vez de concentrar a riqueza gerada com a comercialização de alimentos, por meio dos mercados institucionais as cooperativas promovem a distribuição dos benefícios gerados com a comercialização, o que contribui para o empoderamento dos agricultores/as.

Uma situação presente em muitas cooperativas é a quase dependência dos mercados institucionais. De um lado, é ali onde mais se abriu espaço para a compra da diversidade dos produtos da agricultura familiar agroecológica; de outro, ela gerou uma vinculação e quase dependência dos agricultores e famílias envolvidos. A preocupação com esta dependência foi manifestada por todos os dirigentes das cooperativas, como é evidenciado na fala a seguir: "temos dependência do mercado institucional e temos consciência disso. [...]. A própria Conab diz: vocês não podem ficar dependentes do PAA, ele é apenas uma escola que permite aprendizado e qualificação do processo de produção e comercialização" (Cooperativa 05).

Para diversas cooperativas, o PAA é um circuito comercial de suma importância, como é evidenciado na fala a seguir: "[...] essa cooperativa talvez exista justamente pelo PAA [...], dependemos do PAA para continuar sobrevivendo e precisamos que ele nos ajude mais" (Cooperativa 03). Em outra situação estudada, assim foi relatado: "ainda não construímos outro mercado, o primeiro mercado que foi organizado pra fazer a venda é o mercado institucional para a comercialização da diversidade. [...] não alcançamos outros mercados [...]" (Cooperativa 07).
Uma dependência dos mercados institucionais caracteriza um sério problema. Para muitas cooperativas da rede estudada, este é o principal circuito comercial acessado e único canal montado capaz de absorver, em quantidade, a ampla diversidade de alimentos. Além deste risco de "colocar todos os ovos numa única cesta", os atrasos no repasse de recursos às cooperativas e na aprovação de novos projetos impactam negativamente as organizações, como fica claro na fala a seguir: "Faz cinco meses que estamos aguardando aprovar novo projeto $e$ não há expectativa ainda" (Cooperativa 03).

Para as organizações da agricultura familiar que dependem dos mercados institucionais para a comercialização de alimentos, problemas como os apontados podem gerar perda de produção e comprometimento da renda familiar, podendo, inclusive, desestruturar os processos de transição para sistemas agroecológicos. Deste modo, no contexto dos casos estudados, considerando a contribuição que os mercados institucionais deram à compra da diversidade de produtos, com prioridade àqueles do território próximo, fica evidente a necessidade de seu aperfeiçoamento e ampliação. São programas que têm amplos efeitos sociais e econômicos, com impacto na esfera ambiental, quando favorecem a produção diversificada e a venda no mesmo território onde ocorreu a produção. Tais programas poderiam ter uma base institucional mais profissionalizada, estável, que desse segurança jurídica e produtiva aos agricultores familiares e suas organizações.

Contudo, também é evidente a necessidade de uma reorganização das cooperativas, aproveitando o aprendizado adquirido junto às práticas comerciais dos mercados institucionais, para conquistarem outros mercados que valorizem sua diversidade produtiva. Ademais, destacamos a necessidade de apoio na forma de créditos subsidiados, por meio da 
iniciativa pública, para qualificação dos processos comerciais das cooperativas.

Observamos que todas elas enfrentam algum grau de deficiência estrutural, sendo que as nove que integram os grupos $A$ e $B$ enfrentam a situação mais crítica. Elas são organizações recentes e os mercados institucionais foram fundamentais para viabilizá-las nestes anos iniciais. Entretanto, elas ainda carecem de máquinas, equipamentos, caminhões, instalações agroindustriais, etc., que permitiriam avançar nas atividades comerciais. Isto permitiria não só abrir novos espaços para a comercialização da ampla diversidade de alimentos, mas uma maior eficiência comercial, essencial para aproveitar as oportunidades de mercado.

No âmbito das políticas públicas voltadas a uma agricultura sustentável, entendemos que, além dos mercados institucionais, seria crucial que se avançasse no pagamento por serviços ambientais aos agricultores familiares agroecológicos. Isto poderia gerar um círculo virtuoso, priorizando a conservação da biodiversidade, a preservação dos mananciais hídricos e da beleza cênica, além da fixação de carbono, promovidas pela produção diversificada e pelos mercados de proximidade.

\section{Conclusões}

A rede de cooperativas de reforma agrária apresenta um processo heterogêneo de construção

\section{Referências}

Altieri, M. Agroecologia: bases científicas para uma agricultura sustentável. 3. ed. rev. ampl. São Paulo: Expressão Popular, 2012. 400 p.

Altieri, M.; Nicholls, C. Agroecology and the searche for a truly sustainable agriculture. PNUMA. 1. ed. México (DF), 2005. das dinâmicas comerciais, sendo que algumas atuam pautadas por lógicas dominantes de organização comercial, enquanto outras efetivam práticas que se aproximam da abordagem agroecológica. Observa-se em parte desta rede uma clara convencionalização promovida por suas dinâmicas comerciais, gerando especialização e venda para mercados distantes do local de produção. Em outra parte, se vê a valorização da diversidade e dos mercados de proximidade, entretanto, com forte dependência dos mercados institucionais. Assim, se algumas se afastariam da abordagem agroecológica por uma sujeição às lógicas dominantes do mercado, sem elaborar alternativas que valorizem a produção diversificada de seus agricultores, outras vivem o risco da dependência dos mercados institucionais.

A diversidade de situações revela um limite de planejamento integrado e estratégico entre as cooperativas. Tal planejamento poderia aproveitar o aprendizado coletivo, seja nas exigências postas pelas formas convencionais de mercado, seja naquelas dos mercados institucionais e de proximidade, avançando na conquista de espaços mercantis e mantendo a prioridade à agroecologia. Um planejamento apropriado poderia potencializar as complementaridades entre CCC e CLC, organizando logísticas e ações que valorizassem os primeiros. Ampliar a escala comercial e se especializar não precisam ser sinônimos de restringir a diversidade produtiva e comercial a níveis não agroecológicos.
Bezerra, I.; Schneider, S. Produção e consumo de alimentos: o papel das políticas públicas entre o plantar e o comer. Faz Ciência, 14(19), 35-61, 2012.

Brasil. Decreto ${ }^{\circ} 6.447$, de 7 de maio de 2008. Regulamenta $\mathrm{o}$ art. 19 da Lei $\mathrm{n}^{\circ} 10.696$, de 2 de julho de 2003, que institui o Programa de Aquisição de Alimentos. Brasília, 2008. 
Brasil. Ministério da Saúde. Secretaria de atenção à saúde. Guia Alimentar para a População Brasileira. 2. ed. Brasília, 2014. $158 \mathrm{p}$.

Brasil. Secretaria da Agricultura e do Abastecimento. Programa Leite das Crianças. 2015. Disponível em: <http:// www.leitedascriancas.pr.gov.br/>. Acesso em: 20 fev. 2015.

Canuto, J. C. Política de pesquisa com enfoque agroecológico como resposta aos riscos socioambientais da convencionalização das agriculturas ecológicas no Brasil. In: Anais do Encontro Internacional sobre Agroecologia e Desenvolvimento Rural Sustentável. Botucatu: UNESP, 2001.

Comunello, F. J. Os movimentos nos mercados: a formação dos circuitos agroecológicos e orgânicos. In: Anais do V Encontro Nacional de Estudos do Consumo. Rio de Janeiro, 15, 16 e 17 de setembro de 2010. Rio de Janeiro/ RJ. Disponível em: <http://estudosdoconsumo.com.br/wp-content/uploads/2010/09/1. 5-_Feli..1.pdf $>$.

Darolt, M. R. Circuitos curtos de comercialização de alimentos ecológicos: Reconectando produtores e consumidores. In: Niederle, P. A.; Almeida L.; Vezzani, F. M. (Org.). Agroecologia: práticas, mercados e políticas para uma nova agricultura. Curitiba: Kairós, 2013, p. 139-170.

Darolt, M. R.; Lamine, C.; Brandenburg, A. A diversidade dos circuitos curtos de alimentos ecológicos: Ensinamentos do caso brasileiro e francês. Revista Agriculturas, 10(2), 8-13, 2013. Disponível em:<http://aspta.org.br/wp-content/ uploads/2013/09/Revista-Agriculturas-V10N2-Artigo-1. pdf $>$.

FAO - Food and Agriculture Organization of the United Nations. Os rastros do desperdicio de alimentos: impactos sobre os recursos naturais. Roma, 2013. Disponível em: https://www.fao.org.br/daccatb.asp.

Flexor, G. A. Globalização do sistema agroalimentar e seus desafios para o Brasil. Revista Economia Ensaios, 20(2) e 21(1), 63-95, 2006. Disponível em: <http://www. seer.ufu.br/index.php/revistaeconomiaensaios/article/ view/1554/1381>.

Gondim, S. M. G. Grupos focais como técnica de investigação qualitativa: desafios metodológicos. Paidéia, 12(24), 149-161, 2002. Disponível em: <http://www.scielo.br/ scielo.php?script=sci_arttext\&pid=S0103-863X2002000 $300004 \& \operatorname{lng}=$ en\&nrm $=$ iso $>$.
Goodman, D.; Sorj, B.; Wilkinson, J. Da lavoura às biotecnologias: agricultura e indústria no sistema internacional. Biblioteca Virtual de Ciências Humanas. Centro Edelstein de Pesquisas Sociais. Ipanema - Rio de Janeiro - RJ, 2008.

Guivant, J.; Spaargaren, G.; Rial, C. (Org.). Novas práticas alimentares no mercado global. Florianopolis: Ed. UFSC, 2010.

Guthman, J. The Trouble with 'Organic Lite' in California: a Rejoinder to the 'Conventionalisation' Debate. Sociologia Ruralis, 44(3), 301-316, 2004. Disponível em: <http://onlinelibrary.wiley.com/doi/10.1111/j.14679523.2004.00277.x/epdf>.

Junior, N. N. G.; Junior, O. A.; Silva, R. P.; S. Junior, A. O. S. Políticas públicas de segurança alimentar e o combate à exclusão socioeconômica: a importância da comercialização agrícola. In. Bergamasco, S. M. P.; Sampaio, M. F. A. (Orgs.). Sistemas agroalimentares: análises e perspectivas para a América Latina. Campinas, SP: Unicamp, 2003. p. 139-155.

Lamine, C.; Darolt, M.; Brandenburg, A. The Civic and Social Dimensions of Food Production and Distribution in Alternative Food Networks in France and Southern Brazil. International Journal of Sociology of Agriculture and Food, 19(3), 383-401, 2012. Disponível em: <http://ijsaf.org/ archive/19/3/lamine.pdf $>$.

Machado, L. C. P.; Filho, L. C. P. M. A dialética da agroecologia: contribuição para um mundo com alimentos sem veneno. São Paulo: Expressão Popular, 2014. 360 p.

Maluf, R. S. Mercados agroalimentares e agricultura familiar no Brasil: agregação de valor, cadeias integradas e circuitos regionais. Ensaios FEE, 25(1), 299-322, 2004.

Niederle, P. A.; Almeida, L. A nova arquitetura dos mercados para produtos orgânicos: o debate da convencionalização. In: Niederle, P. A.; Almeida L.; Vezzani, F. M. (Org.). Agroecologia: práticas, mercados e políticas para uma nova agricultura. Curitiba: Kairós, 2013, p. 23-69.

Pascucci, S. Governance structure, perception and innovation in credence food transactions: The role of food community networks. International Journal on Food System Dynamics, 3, 224-236, 2010. Disponível em: <http:// centmapress.ilb.unibonn.de/ojs/index.php/fsd/article/ view/136/90>. 
Perez-Cassarino, J. P.; Ferreira, A. D. D. Agroecologia, construção social de mercados e a constituição de sistemas agroalimentares alternativos: uma leitura a partir da rede eco vida de agroecologia. In: Niederle, P.; Almeida, L.; Vezzani, F. M. (Orgs). Agroecologia: práticas, mercados e políticas para uma nova agricultura. Curitiba: Kairós, p. 171-213, 2013.

Popkin, B. M. O mundo está gordo: modismos, tendências, produtos e políticas que estão engordando a humanidade. Rio de Janeiro: Elsevier, 2009.

Proença, R. P. C. Alimentação e globalização: algumas reflexões. Ciência e Cultura, 62(4), 2010. Disponível em: $<$ http://cienciaecultura.bvs.br/scielo.php?script=sci arttext\&pid=S0009-67252010000400014\&lng=en\&nrm $=$ iso $>$.

Renting, H.; Schermer, M.; Rossi, A. Building food democracy: exploring Civic Food Networks and newly emerging forms of food citizenship. International Journal of Sociology of Agriculture and Food, 19(3), 289-307, 2012. Disponível em: <http://ijsaf.org/archive/19/3/renting.pdf> .

Santos, F.; Tonezer, C.; Rambo, A. G. Agroecologia e agricultura familiar: um caminho para a soberania alimentar? In: Anais do $47^{\circ}$ Congresso da Sociedade Brasileira de Economia, Administração e Sociologia Rural - SOBER. Porto Alegre, 26 a 30 de julho de 2009. Disponível em: $<$ http://www.sober.org.br/palestra/13/549.pdf>.

Sato, G. S. Globalização e diferenciação no consumo alimentar. Revista Análises e Indicadores do Agronegócio, 4(6), 2009. Disponível em: <http://www.iea.sp.gov.br/out/ LerTexto.php?codTexto $=10653>$.

Schmitt, C. J. Encurtando o caminho entre a produção e o consumo de alimentos. Revista Agriculturas: Experiências em Agricultura, 8(3), 04-08, 2011. Disponível em: <http:// aspta.org.br/revista/v8-n3-relocalizando-os-sistemas-agroalimentares/>. 